\title{
Yanıt Yüzey Yöntemi ve Genetik Algoritma ile Tufal ilaveli Harçların Basınç Dayanımın Optimizasyonu
}

\author{
Erdinç ARICI ${ }^{1 *}$, Oğuzhan KELEŞTEMUR ${ }^{2}$ \\ ${ }^{1}$ İnşaat Mühendisliği Bölümü, Teknoloji Fakültesi, Fırat Üniversitesi, Elazığ, Türkiye \\ 2 İnşaat Mühendisliği Bölümü, Teknoloji Fakültesi, Fırat Üniversitesi, Elazığ, Türkiye \\ *1 earici1@firat.edu.tr, 20kelestemur@firat.edu.tr
}

\begin{abstract}
Öz: Bu çalışmada, yanıt yüzey yöntemi (YYY) ve genetik algoritma kullanılarak tufal ilaveli harçların basınç dayanımının optimizasyonu yapıldı. Deney serilerinin belirlenmesinde ve deneysel verilerin analizinde YYY kullanıldı. Farklı oranlarda tufal içeren 25 seri harç numunesi hazırlandı ve bunların basınç dayanımları belirlendi. Yanıt yüzey yöntemi ile deneysel verilerin analizleri yapılarak matematiksel bir model oluşturuldu. Genetik algoritma kullanılarak bu modelin optimizasyonu yapıldı ve optimum parametre değerleri belirlendi. Optimizasyon sonucu ile kıyaslamak için doğrulama deneyi yapıldı ve \% 90'nın üstünde korelasyon olduğu gözlendi. Bu çalıșma sonucunda, YYY ve genetik algoritmanın birlikte kullanılarak daha az deney ile güvenilir optimizasyon yapılabileceği görüldü.
\end{abstract}

Anahtar Kelimeler: Yanıt yüzey yöntemi, Genetik algoritma, ANOVA, Tufal, Harç, Basınç dayanımı

\section{Optimization of Compressive Strength of Mortars with Steel Scale by Using Response Surface Method and Genetic Algorithm}

\begin{abstract}
In this study, compressive strength of mortar specimens containing steel scale was optimized by using response surface method (RSM) and genetic algorithm. RSM was used in the determination the experiment series and analysis of experimental data. 25 series mortar samples containing different ratios steel scale were prepared and the compressive strength of these series was determined. A mathematical model was created by analyzing the experimental data with response surface method. This model was optimized by using genetic algorithm and optimum parameter values were determined. Confirmation test was done to compare with the optimization result and it was observed that the correlation was over $90 \%$. As a result of this study, it was observed that it could to make reliable optimization with less experiment by using of combination of RSM and genetic algorithm.
\end{abstract}

Keywords: Response surface method, Genetic algorithm, ANOVA, Steel scale, Mortar, Compressive strength

\section{Giriş}

$\mathrm{Su}$, çimento ve agreganın karışımından meydana gelen beton inşaat sektöründe farklı kullanım alanlarına sahiptir. Fakat betonun gevrek ve geçirgen yapıya sahip olması kullanım yerine bağlı olarak bazı olumsuzluklara sebep olmaktadır. Bu olumsuzlukları ortadan kaldırmak veya azaltmak amacıyla farklı malzemeler veya katkılar beton karışımına ilave edilerek dayanım ve dayanıklılık özelliklerinin iyileştirmesi yoluna gidilir [1].

Beton ve harçlarda büyük miktarda ince agrega tüketir. Bu, nehir kumunun kontrolsüz bir şekilde kullanımına yol açmaktadır. İnşaat sektöründeki yoğun talep nedeniyle doğal kuma alternatif bulmak amacıyla özellikle atık malzemelerin kullanımı yoluna gidilmiştir [2].

Çevreyi atıklardan korumak insan, hayvan ve bitki sağlığı için çok önemlidir. Bu amaçla bilim insanları hem atıkları kullanmanın hem de doğal kaynakların tüketimini sınırlandırmanın alternatif yollarını araştırmaktadırlar. Son yıllarda sınai yan ürünler veya atıklar çimento esaslı malzemelerde çimento veya agrega olarak kullanılmaktadır [3]. Beton ve harçlarda kullanımının araştırıldığg malzemelerden biride çelik tufalidir.

Demir cevherinin işlemesi sonucu elde edilen çelik dünyada en yaygın kullanılan malzeme olarak kabul edilir. Sıcak haddeleme işlemi sırasında, çelik yüzeyinde tufal adı verilen bir oksit tabakası oluşur. Çevre üzerinde olumsuz etkilere de sahip olan çelik tufali çelik üretim sürecince tonlarca oluşmaktadır [4].

Ayrıca, tehlikeli atıklar içerisinde en büyük hacme sahip sürekli dökümler ve sıcak haddehaneler su resirkülasyon tesislerinden açığa çıkan yağlı tufalin Tehlikeli Atıkların Kontrolü Yönetmeliği’ne göre bertarafının sağlanması için $50 \mathrm{mx100} \mathrm{m}$ boyutlarında toprak dolgu tesisinin inşa edilmesi gerekmektedir. Böylece, bu atıkların bertarafının, depolanmasının ya da geri kazanımının yasal platformda da yer aldığı gözlenebilmektedir [5].

\footnotetext{
${ }^{*}$ Sorumlu yazar: earici1@ firat.edu.tr. Yazarların ORCID Numaraları: ${ }^{1}$ 0000-0002-6153-5805, ${ }^{2}$ 0000-0002-8498-7660
} 
Tufal gibi atık malzemelerin hem ekonomiye kazandırılması hem de çevresel zararlarının azaltılması amacıyla farklı alanlarda çalışmalar yapılmıştır [6-8]. Bu amaca yönelik deneysel çalışmalarda en büyük zorluk yorum yapılabilmesi için fazlasıyla zaman ve deneysel veriye ihtiyaç duyulmasıdır. Daha kısa sürede ve daha az deneysel veriyle sonuçlara ulaşabilmek ve yorumlamanın yapılabilmesi için istatistiksel analiz yöntemlerinden faydalanılmaktadır. Bu yöntemlerden biride Yanıt Yüzey Yöntemidir (YYY).

Yanıt yüzey yöntemi, deneysel tasarım ve elde edilen deneysel verilere ampirik modellerin uygunluğuna dayanan matematiksel ve istatistiksel tekniklerin bir kombinasyonunu içerir. Bu nedenle, parametre optimizasyonu için YYY metodolojisi önerilmiştir [9]. YYY'nin amacı, giriş parametreleri dikkate alınarak yanıtın (çıktı parametresi) optimizasyonudur. 1951 yllında Box ve Wilson tarafından önerilen YYY, ilk önce kimya alanında kullanıldı [10]. Fakat deneysel çalışmalara sağladığı büyük avantajlarından dolayı birçok alanda uygulanmıştır [11-13].

Genel olarak yanıt yüzey yöntemi 3 aşamadan (eleme denemeleri, bölge araştırması ve işlemin veya ürünün optimizasyonu) oluşmaktadır. Eleme denemeleri, daha az sayıda ve daha verimli esas deneme yapılmasına olanak sağlamaktadır. İkinci aşama olan bölge araştırmasında amaç, eleme denemeleri ile belirlenen bağımsız değişkenlerin sistemin yanıtında oluşturdukları değerlerin, optimum noktaya yakın sonuçlar verip vermediğini belirlemektir. Yanıt yüzey yönteminin üçüncü aşaması, işlem optimum noktaya yaklaşıldığında başlar. Gerçek yanıt fonksiyonu optimum nokta etrafında önemli bir eğrilik göstermektedir. Bu eğrilik tahmin edilirken; lineer olmayan modeller, genellikle ikinci dereceden polinomsal modeller, üssel modeller veya eksponensiyel modeller kullanılır. Uygun bir model elde edildikten sonra, bu model optimum noktanın araştırılmasında kullanılır [14]. Yanıt, bağımsız değişkenlerin doğrusal bir işlevi ile iyi bir şekilde modellenirse, Denklem 1'de verilen birinci dereceden denklemle modelleme yapılır [15].

$y=\beta_{0}+\beta_{1} x_{1}+\beta_{2} x_{2}+\beta_{3} x_{3}$

Birinci dereceden denklemle yapılan modellemede değişkenler birbirinden etkileniyorsa yanıt polinomu Denklem 2'de verilen denklemle modelleme yapılır.

$y=\beta_{0}+\beta_{1} x_{1}+\beta_{2} x_{2}+\beta_{3} x_{3}+\beta_{4} x_{1} x_{2}+\beta_{5} x_{1} x_{3}+\beta_{6} x_{2} x_{3}$

Model yapısı doğrusal bir polinom ile yapılamıyorsa ikinci derece bir denklem ile modelleme yoluna gidilir. Bu modele ait temel formül Denklem 3'de verilmiştir [16].

$y=\beta_{0}+\beta_{1} x_{1}+\beta_{2} x_{2}+\beta_{3} x_{3}+\beta_{4} x_{1}^{2}+\beta_{5} x_{2}^{2}+\beta_{6} x_{3}^{2}+\beta_{7} x_{1} x_{2}+\beta_{8} x_{1} x_{3}+\beta_{9} x_{2} x_{3}$

Denklemlerde;

$\mathrm{y}=$ tahmin edilen yanıt (Basınç dayanımı),

$\mathrm{x}=$ parametreler,

$\beta_{0}=$ sabit katsay 1 ,

$\beta_{1}, \beta_{2}, \beta_{3}=$ Parametrelerin katsayılarıdır.

Model denklem elde edildikten sonra genetik algoritma kullanılarak maksimum veya minimum yanıt değerine ulaşmak için parametrelerin optimum değerleri belirlenir. Genetik algoritma minimum hata ile optimum değerlere ulaşılabilme imkanı sağlamaktadır.

Genetik Algoritma tekniği, karmaşık mühendislik optimizasyon problemlerini çözmek için kullanılır. Genetik Algoritmalar (GA) fikri ilk olarak 1975 yılında John Holland tarafından başlatılmıştır. Genetik algoritma, kimya, fizik, mekanik, aerodinamik, robotik, ağlar, mimarlık ve inşaat mühendisliği gibi birçok mühendislik alanında kullanılmaktadır [17].

GA'ları kör bir arama motoruna benzetebiliriz. GA'lar problemin yapısına bakmaksızın çok karmaşık optimizasyon problemleri için bile çözüm bulabilirler. Problemin karmaşıklığı GA'lar için hiç önemli değildir. GA'ların ihtiyaç duyduğu şey problemin karar değişkenlerinin uygun bir yöntemle kodlanması ve neyin iyi olduğunu GA'ya belirtmek üzere tasarlanan bir uygunluk (amaç) fonksiyonudur. GA’lar çözüm uzayını taramaya bir topluluk ile başladıkları için global optimum çözüme yaklaşmak diğer yöntemlere göre daha kolay olmaktadır. GA'lar bir topluluk (başlangıçta bu topluluk genelde rastgele oluşturulur) ile başlar ve bu topluluk üzerinde çaprazlama, seçme ve mutasyon gibi yöntemlerin uygulanmasıyla problemin her aşamasında en iyiye doğru bir gidiş sağlanır [18]. 
Genetik algoritmanın başlangıcında parametrelerin, uygunluk fonksiyonunun ve durdurma kriterinin tanımlanması gerekir. Daha sonra, parametrelerin temsili, başlangıç popülasyonunun oluşturulması, uygunluk veya kalitenin değerlendirilmesi, tekrar üreme, çaprazlama ve mutasyon gibi genetik işlemlerin yapılması gerekir. Durdurma kriteri sağlanınca optimum çözüm bulunmuş olur. Başlangıç yoğunluğunun üretilmesini takiben, her çözümün uygunluğu veya iyiliği, seçilen bir uygunluk fonksiyonu kullanılarak değerlendirilir. Uygunluk fonksiyonu, eldeki veriler dikkate alınarak belirlendiği için, bunun seçimi probleme bağlıdır. Uygunluk ölçekleme işlemi, bazen daha iyiyi seçmek için elde edilen iyi çözümlerden daha iyi çözümlere kadar devam ettirilen bir işlemdir. Seçme, çaprazlama ve mutasyon gibi genetik operatörler, elde edilen iyi çözümlerden denenmiş yeni çözümler üretmek için kullanılırlar. Bu iyileştirme işlemi, daha önceden belirlenen bir jenerasyon sayısına veya tatmin edici bir sonuca ulaşıncaya kadar devam ettirilir. Çaprazlama operatörü, var olan iki çözümün uzantılarının belirli bir noktadan itibaren yer değiştirmesi ile denenmemiş yeni iki çözüm üretir. Mutasyon operatörü ise, var olan bir çözümün herhangi bir bitinin terslendirilmesi ile yeni bir çözüm üretir. Genetik algoritmanın işlem akış diyagramı Şekil 1'de gösterilmiştir [19].

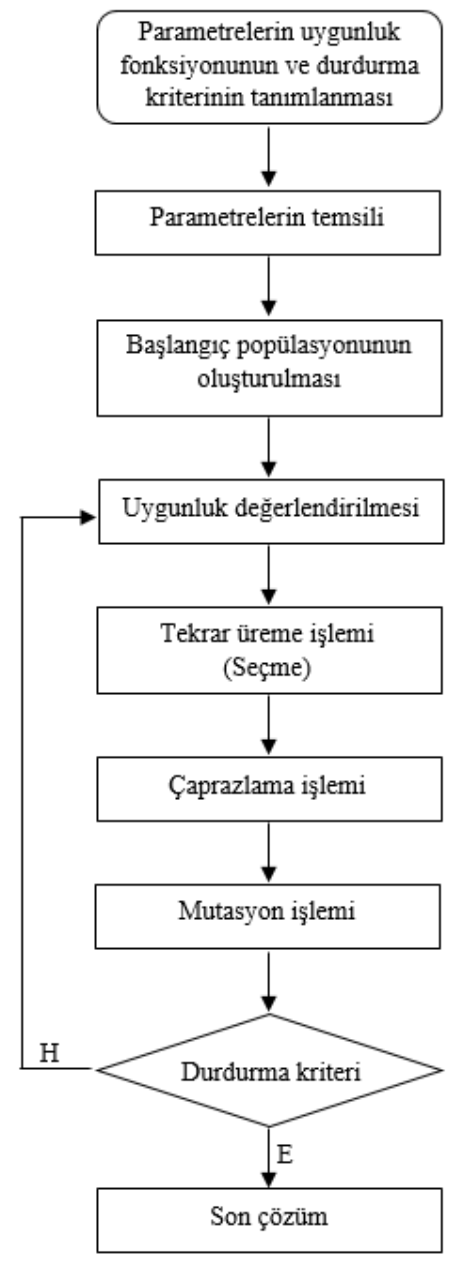

Şekil 1. Genetik algoritma akış diyagramı.

$\mathrm{Bu}$ çalışmanın amacı; yanıt yüzey metodu kullanılarak tufal ilaveli harçların basınç dayanımının optimizasyonunu yapmaktır. Maksimum basınç dayanımının elde edilebileceği parametre seviyelerinin belirlenmesinde YYY ve genetik algoritma kullanıldı. YYY ile oluşturulan model denkleme genetik algoritma uygulanarak maksimum basınç dayanımının elde edilebileceği parametre seviyeleri belirlendi. Genetik algoritma sonucu belirlenen optimum parametre seviyelerine göre hazırlanan numuneler üzerinde basınç dayanımı deneyi yapıldı. Tahmini sonuç ile deney sonucu kıyaslanarak yorumlaması yapıldı. Bu çalışma, istatistiksel yöntemler 
kullanılarak deneysel çalışmaların daha kısa sürede sonuçlanabileceğini ve daha sağlıklı olarak yorumlanabileceğini göstermesi açısından literatüre olumlu katkı sağlayacaktır.

\section{Materyal ve Metot}

\subsection{Materyal}

Deney serilerinin hazırlanmasında maksimum agrega çap $14 \mathrm{~mm}$ olan dere agregası kullanılmıștır. Kullanılan agreganın elek analiz değerleri Tablo 1'de verilmiştir. Bağlayıcı malzeme olarak TS EN 197-1 standardına uygun CEM I $42.5 \mathrm{~N}$ tipi çimento kullanılmıştır [20].

Tablo 1. Agrega elek analizi değerleri

\begin{tabular}{|c|c|}
\hline Elek çapı $\mathbf{( m m})$ & Elekten geçen $\mathbf{( \% )}$ \\
\hline 4 & 100 \\
\hline 2 & 71 \\
\hline 1 & 50 \\
\hline 0.5 & 35 \\
\hline 0.25 & 25 \\
\hline
\end{tabular}

Agrega ile yer değiş̧irilecek olan çelik tufali Şekil 2a'da görüleceği üzere yassı şekilli olmasından dolayı karışım içerisine doğrudan katılamadı. Bu sebeple öğütülerek kullanılabilir duruma getirildi. Şekil $2 \mathrm{~b}$ 'de görülen tufal $0.25 \mathrm{~mm}$ 'lik ve $1 \mathrm{~mm}$ 'lik eleklerden elenerek ince ve iri tufal olmak üzere iki guruba ayrıldı.

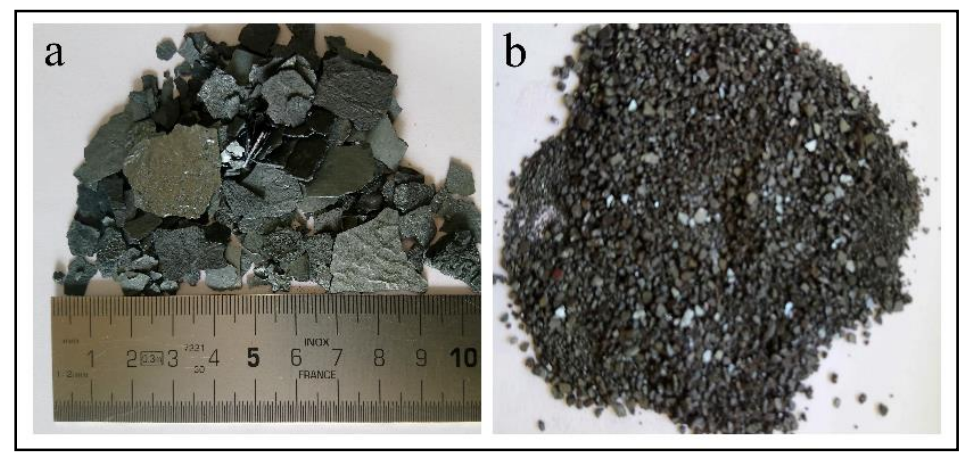

Şekil 2. Doğal ve öğ̈üülmüş tufal.

Deney serilerinin basınç dayanımları belirlenmesi için her seriden 50x50x50 mm boyutunda TS EN 196-1 de belirtilen harç karışım esaslarına uygun numuneler hazırlandı [21]. Hazırlanan numuneler 28 gün kirece doygun kür ortamında bekletildikten sonra basınç dayanımı deneyine tabii tutuldu.

\subsection{Metot}

Yanıt yüzey yönteminde ilk aşama deneysel tasarımdır. İstatistiksel tasarım olarak bilinen bu aşamada, en az sayıda deneyle maksimum bilgi elde etmek için deneylerin nasıl planlanacağı ve yapılacağının belirlendiği bölümdür. Daha önce tasarım taraması yapılarak etkinliği araştırılan parametrelerin hangi seviyede kullanılacağı belirlendikten sonra, herhangi bir tasarım seçimi yapılmadan önce aşağıdaki sorular cevaplanmalıdır [22].

1. Parametrelerin etkisi ve yanıt değerleri nasıl ölçülecek?

2. Yanıt değeri üzerinde kaç tane parametre etkin olacak?

3. Kaç adet parametre eş zamanlı olarak dikkate alınacak?

4. Deneysel olarak kaç adet tekrara ihtiyaç olacak?

5. Hangi tip veri analizine ihtiyaç var? 
Yanıt yüzey yöntemi ile optimizasyon yapılabilmesi için ilk önce parametreler ve seviyeleri belirlendi. Yanıt değeri üzerinde etkili olacak ince tufal $(0-0.25 \mathrm{~mm})$, iri tufal $(0.25-1 \mathrm{~mm})$, Su/Çimento oranı $(\mathrm{S} / C ̧)$ ve çimento dozaj1 olmak üzere Tablo 2'de verilen dört parametre esas alındı.

Tablo 2. Parametreler ve seviyeleri

\begin{tabular}{|l|c|c|c|c|c|c|c|}
\hline \multicolumn{1}{|c|}{ Parametreler } & \multirow{2}{*}{ Sembol } & \multirow{2}{*}{ Birim } & \multicolumn{5}{c|}{ Seviyeler ve kodları } \\
\cline { 4 - 8 } & & & $\mathbf{- 2}$ & $\mathbf{- 1}$ & $\mathbf{0}$ & $\mathbf{1}$ & $\mathbf{2}$ \\
\hline İnce tufal $(0-0.25 \mathrm{~mm})$ & $\mathrm{A}$ & $\%$ & 0 & 5 & 10 & 15 & 20 \\
\hline İi tufal $(0.25-1 \mathrm{~mm})$ & $\mathrm{B}$ & $\%$ & 0 & 5 & 10 & 15 & 20 \\
\hline Su/Çimento oranı & $\mathrm{C}$ & & & 0.50 & 0.55 & 0.60 & \\
\hline Çimento Dozaj1 & $\mathrm{D}$ & $\left(\mathrm{kg} / \mathrm{m}^{3}\right)$ & & 400 & 450 & 500 & \\
\hline
\end{tabular}

Yanıt yüzey yöntemi ile analiz işleminin yapılabilmesi için ilk önce Tablo 3'de verilen deney deneysel tasarım planının belirlendi. Modelin güvenilirlik değerinin yüksek olabilmesi için deney tasarım planı belirlenirken yeterli sayıda veri girişi olmasına dikkat edildi.

Tablo 3. Optimum deneysel tasarım planı ve sonuçları

\begin{tabular}{|c|c|c|c|c|c|c|c|c|c|}
\hline \multirow{3}{*}{$\begin{array}{c}\text { Deney } \\
\text { No }\end{array}$} & \multicolumn{8}{|c|}{ Parametre seviyeleri } & \multirow{3}{*}{$\begin{array}{c}\text { Basınç } \\
\text { Dayanımı } \\
\text { (MPa) } \\
\text { (Yanıt) }\end{array}$} \\
\hline & \multicolumn{4}{|c|}{ Kodlanmış değerler } & \multicolumn{4}{|c|}{ Gerçek değerler } & \\
\hline & $\begin{array}{l}\text { Ince } \\
\text { tufal }\end{array}$ & $\begin{array}{c}\text { İri } \\
\text { tufal }\end{array}$ & $\mathbf{S} / \mathbf{C}$ & Dozaj & $\begin{array}{l}\text { İnce tufal } \\
(0-0.25 \mathrm{~mm})\end{array}$ & $\begin{array}{c}\text { İri tufal } \\
(0.25-1 \mathrm{~mm})\end{array}$ & $\mathbf{S} / \mathbf{C}$ & Dozaj & \\
\hline 1 & -1 & -1 & 0 & -1 & 5 & 5 & 0.55 & 400 & 23.08 \\
\hline 2 & 2 & -2 & 0 & -1 & 20 & 0 & 0.55 & 400 & 23.78 \\
\hline 3 & 2 & -2 & -1 & 1 & 20 & 0 & 0.50 & 500 & 28.19 \\
\hline 4 & 0 & 0 & 1 & 0 & 10 & 10 & 0.60 & 450 & 22.42 \\
\hline 5 & -1 & 2 & -1 & -1 & 5 & 20 & 0.50 & 400 & 22.04 \\
\hline 6 & -2 & 2 & 0 & 1 & 0 & 20 & 0.55 & 500 & 21.83 \\
\hline 7 & -1 & 1 & 1 & 1 & 5 & 15 & 0.60 & 500 & 22.18 \\
\hline 8 & -2 & 2 & 1 & 0 & 0 & 20 & 0.60 & 450 & 19.57 \\
\hline 9 & -1 & -2 & 1 & 1 & 5 & 0 & 0.60 & 500 & 23.70 \\
\hline 10 & -2 & -2 & -1 & -1 & 0 & 0 & 0.50 & 400 & 21.70 \\
\hline 11 & -2 & -2 & 0 & 1 & 0 & 0 & 0.55 & 500 & 23.16 \\
\hline 12 & 2 & -1 & -1 & 0 & 20 & 5 & 0.50 & 450 & 26.87 \\
\hline 13 & -2 & -1 & 1 & -1 & 0 & 5 & 0.60 & 400 & 19.94 \\
\hline 14 & 0 & 0 & 0 & 1 & 10 & 10 & 0.55 & 500 & 25.01 \\
\hline 15 & 2 & -2 & 1 & 1 & 20 & 0 & 0.60 & 500 & 24.80 \\
\hline 16 & 1 & 1 & -1 & -1 & 15 & 15 & 0.50 & 400 & 23.87 \\
\hline 17 & 2 & 2 & -1 & 1 & 20 & 20 & 0.50 & 500 & 26.99 \\
\hline 18 & 0 & -2 & 0 & 0 & 10 & 0 & 0.55 & 450 & 23.89 \\
\hline 19 & 1 & 2 & 1 & -1 & 15 & 20 & 0.60 & 400 & 20.37 \\
\hline 20 & 1 & -2 & -1 & -1 & 15 & 0 & 0.50 & 400 & 24.70 \\
\hline 21 & -2 & 2 & 0 & -1 & 0 & 20 & 0.55 & 400 & 19.45 \\
\hline 22 & -2 & 0 & -1 & 1 & 0 & 10 & 0.50 & 500 & 23.82 \\
\hline 23 & 0 & -1 & -1 & 1 & 10 & 5 & 0.50 & 500 & 27.65 \\
\hline 24 & 2 & 0 & 0 & 0 & 20 & 10 & 0.55 & 450 & 24.88 \\
\hline 25 & -2 & 1 & -1 & 0 & 0 & 15 & 0.50 & 450 & 21.98 \\
\hline
\end{tabular}

\section{Bulgular ve Tartışma}

Deneysel tasarım planındaki verilere uygun olarak modelleme yapıldı. Bu basamakta kuadratik modelleme esas alındı. Elde edilen model Denklem 4'de verildi.

Basınç dayanımı $=3.818+0.5 \times A+0.095 \times B+61.18 \times C+0.008 \times D-0.0004 \times A \times B-0.756 \times$ $A \times C-0.0005 \times A \times D-0.195 \times B \times C+0.00004 \times B \times D-0.069 \times C \times D-0.008 \times A^{2}-0.004 \times$ $B^{2}-43.729 \times C^{2}+0.00006 \times D^{2}$ 
Oluşturulan kuadratik modelin Şekil 3'de verilen hata dağılımları incelendiğinde sabit varyansla dağıldığ görülebilir. $\mathrm{Bu}$ durum oluşturulan modelin güvenirliliğini gösterir. Ayrıca modelin regresyon katsayısı $\mathrm{R}^{2}$ değerinin 0.98 ve modeldeki değişim miktarı ölçümünü belirten düzeltilmiş regresyon katsayısı $\mathrm{R}_{\text {adj }}^{2}$ değerinin ise 0.96 olduğu görülür. Bu sonuç oluşturulan kuadratik modelin yanıta uygun olduğunu göstermektedir.

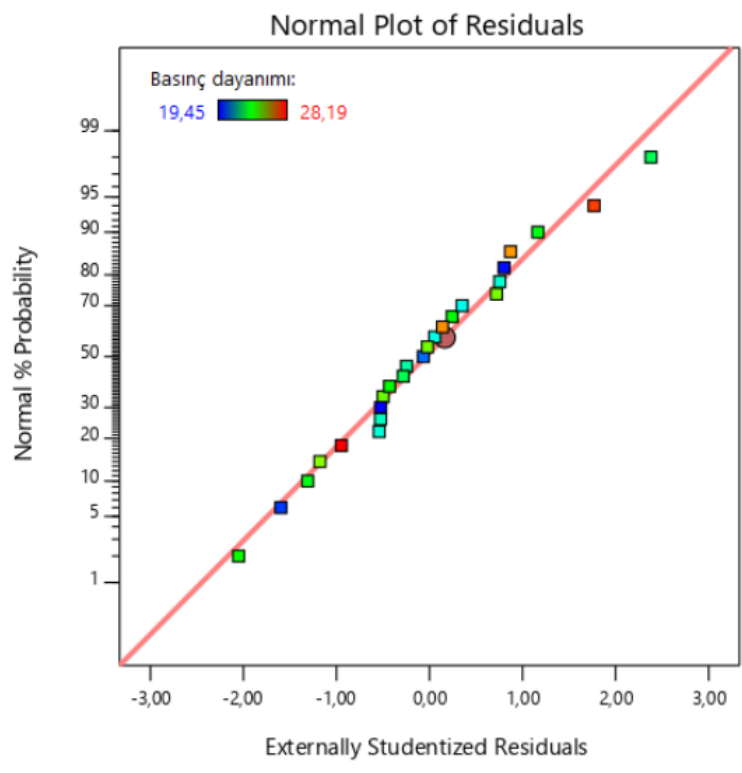

Şekil 3. Hataların dağılım eğrisi.

Elde edilen kuadratik modelin güvenilirliği ve istatistiksel olarak anlamlığının belirlenmesi için Tablo 4'de verilen varyans analizi (ANOVA) yapıldı. Varyans analizi sonucunda elde edilen F oranı ve P değerleri, model ve yanıt üzerinde parametrelerin etkisi hakkında bilgi verebilir.

Tablo 4. Basınç dayanımı (Yanıt) için ANOVA değerleri

\begin{tabular}{|c|c|c|c|c|c|}
\hline Kaynak & $\begin{array}{c}\text { Karelerin } \\
\text { toplamı }\end{array}$ & $\begin{array}{c}\text { Serbestlik } \\
\text { derecesi }\end{array}$ & $\begin{array}{c}\text { Ortalama } \\
\text { kareler }\end{array}$ & F oranı & P değeri \\
\hline Model & 135.72 & 14 & 9.69 & 45.37 & $<0.0001$ \\
\hline $\mathrm{A}$ & 25.74 & 1 & 25.74 & 120.47 & $<0.0001$ \\
\hline $\mathrm{B}$ & 8.31 & 1 & 8.31 & 38.88 & $<0.0001$ \\
\hline $\mathrm{C}$ & 27.23 & 1 & 27.23 & 127.46 & $<0.0001$ \\
\hline $\mathrm{D}$ & 25.05 & 1 & 25.05 & 117.26 & $<0.0001$ \\
\hline $\mathrm{AB}$ & 0.0115 & 1 & 0.0115 & 0.0540 & 0.8209 \\
\hline $\mathrm{AC}$ & 1.20 & 1 & 1.20 & 5.64 & 0.0390 \\
\hline $\mathrm{AD}$ & 0.5927 & 1 & 0.5927 & 2.77 & 0.1268 \\
\hline $\mathrm{BC}$ & 0.0737 & 1 & 0.0737 & 0.3450 & 0.5700 \\
\hline $\mathrm{BD}$ & 0.0046 & 1 & 0.0046 & 0.0213 & 0.8868 \\
\hline $\mathrm{CD}$ & 0.2614 & 1 & 0.2614 & 1.22 & 0.2946 \\
\hline $\mathrm{A}^{2}$ & 2.07 & 1 & 2.07 & 9.70 & 0.0110 \\
\hline $\mathrm{B}^{2}$ & 0.5817 & 1 & 0.5817 & 2.72 & 0.1300 \\
\hline $\mathrm{C}^{2}$ & 0.0556 & 1 & 0.0556 & 0.2602 & 0.6211 \\
\hline $\mathrm{D}^{2}$ & 0.0723 & 1 & 0.0723 & 0.3384 & 0.5736 \\
\hline Residual & 2.14 & 10 & 0.2137 & & \\
\hline Hata & & \multicolumn{2}{l}{} & & \\
\hline Toplam & 120.18 & 26 & & & \\
\hline
\end{tabular}

Tablo 4 incelendiğinde, modelin $\mathrm{F}$ oranının 45.37, P değerinin ise küçük olması $(<0.0001)$ oluşturulan modelin anlamlı olduğunu göstermektedir. Ayrıca A, B, C, D, AC ve A ${ }^{2}$ nin P değerlerinin 0.05 den küçük olması oluşturulacak kuadratik modelin sonuçlarına en etkili değerler olduğunu göstermektedir. 
Denklem 4'de verilen kuadratik denklem modellemesinden elde edilen tahmini sonuçlar ile deney sonuçları (Gerçek değer) arasında farkın çok fazla olmaması gerekir. Analiz sonucunda basınç dayanımı (Yanıt) için tahmini değer ve gerçek değer grafiği Şekil 4'de verilmiştir. Bu grafik incelendiğinde tahmini ve gerçek değer sonuçlarının tutarlı olduğu görülür. Bu durum modellemenin uyumlu olduğunun göstergesidir.

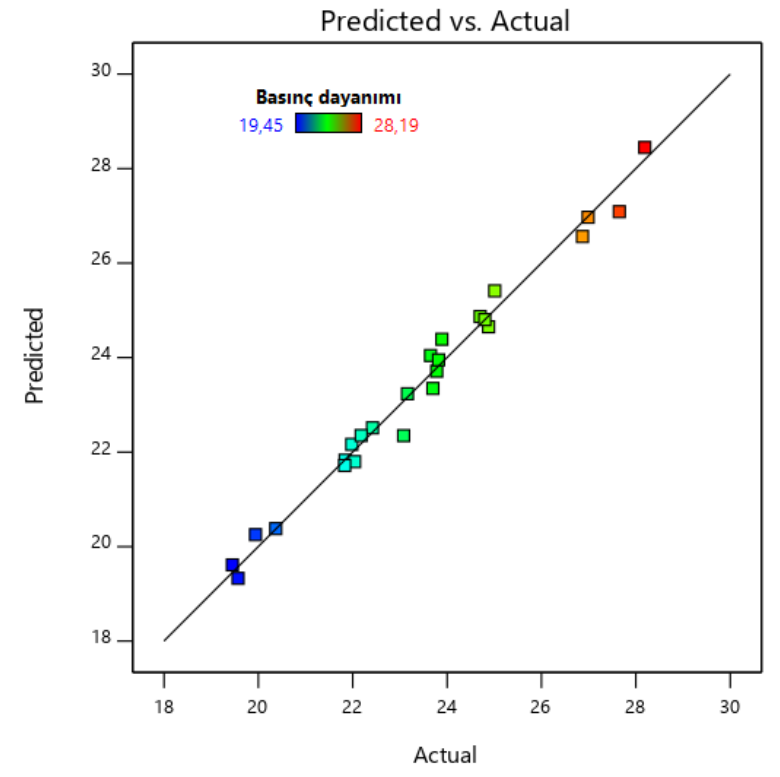

Şekil 4. Basınç dayanımı için tahmini değer-gerçek değer grafiği.

Kuadratik modellemeden faydalanılarak basınç dayanım değişim grafikleri hazırlanmıştır. Şekil 5 ve Şekil 6'da verilen grafikler oluşturulurken parametre merkez değerleri (A0B0C0D0) esas alınmıştır.

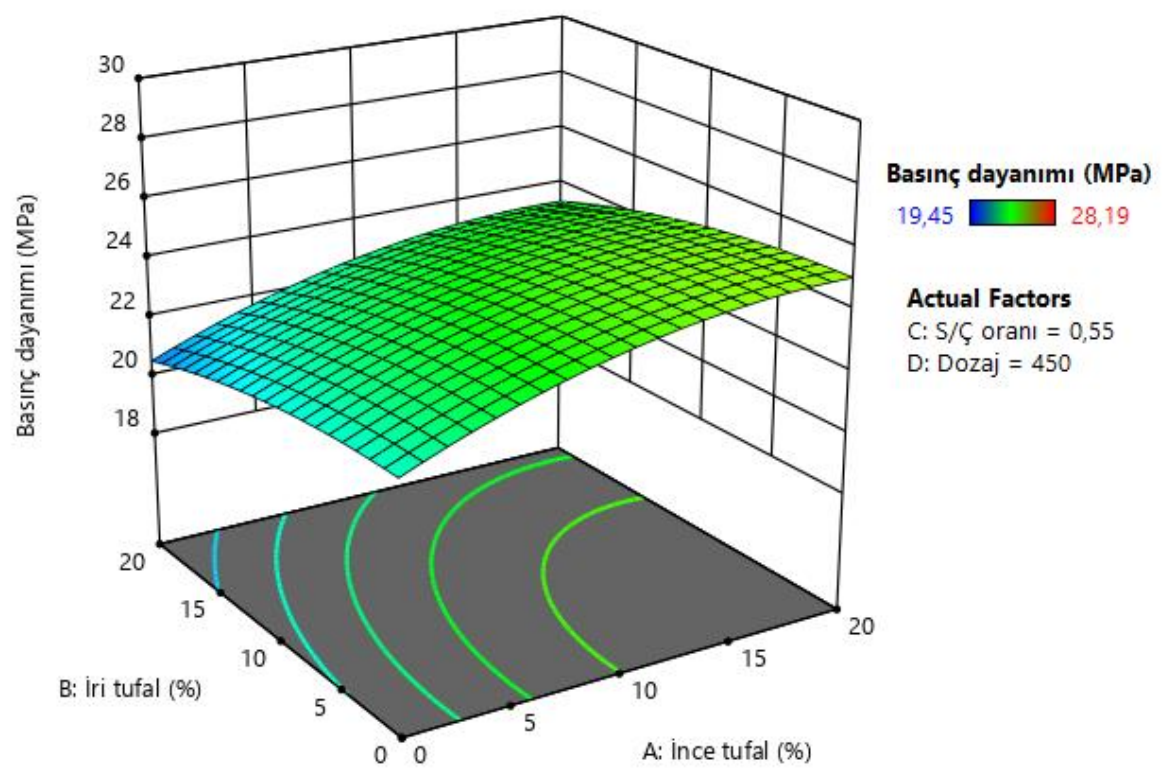

Şekil 5. Basınç dayanımı ile tufal oranı arasındaki ilişki. 


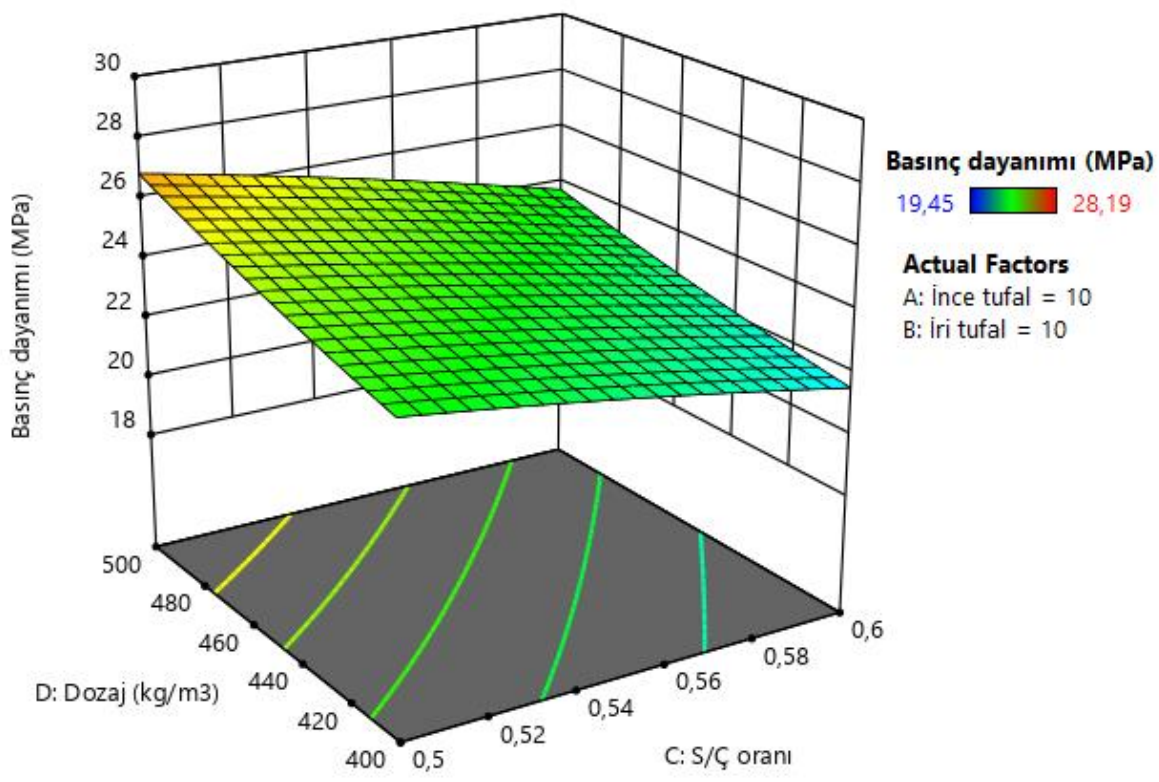

Şekil 6. Basınç dayanımının S/Ç oranı ve dozaja göre değişimi.

Şekil 5 ve Şekil 6 incelendiğinde, ince tufal oranındaki artış basınç dayanımını olumlu yönde etkilerken iri tufal oranındaki artış basınç dayanımını olumsuz yönde etkilemiştir. Aynı şekilde, dozajdaki artışın basınç dayanımını olumlu yönde etkilediği fakat $\mathrm{S} / \mathrm{C}$ oranındaki artışın olumsuz etkilediği görüldü.

Her parametrenin basınç dayanımı üzerindeki etkisinin belirlenebilmesi amacıyla model denklemden faydalanılarak grafikler hazırlandı. Bu grafikler hazırlanırken incelenen parametrenin alt ve üst sınır değerleri arasındaki değişim esas alınırken diğer üç parametrenin merkez nokta seviyesi sabit olarak alındı.
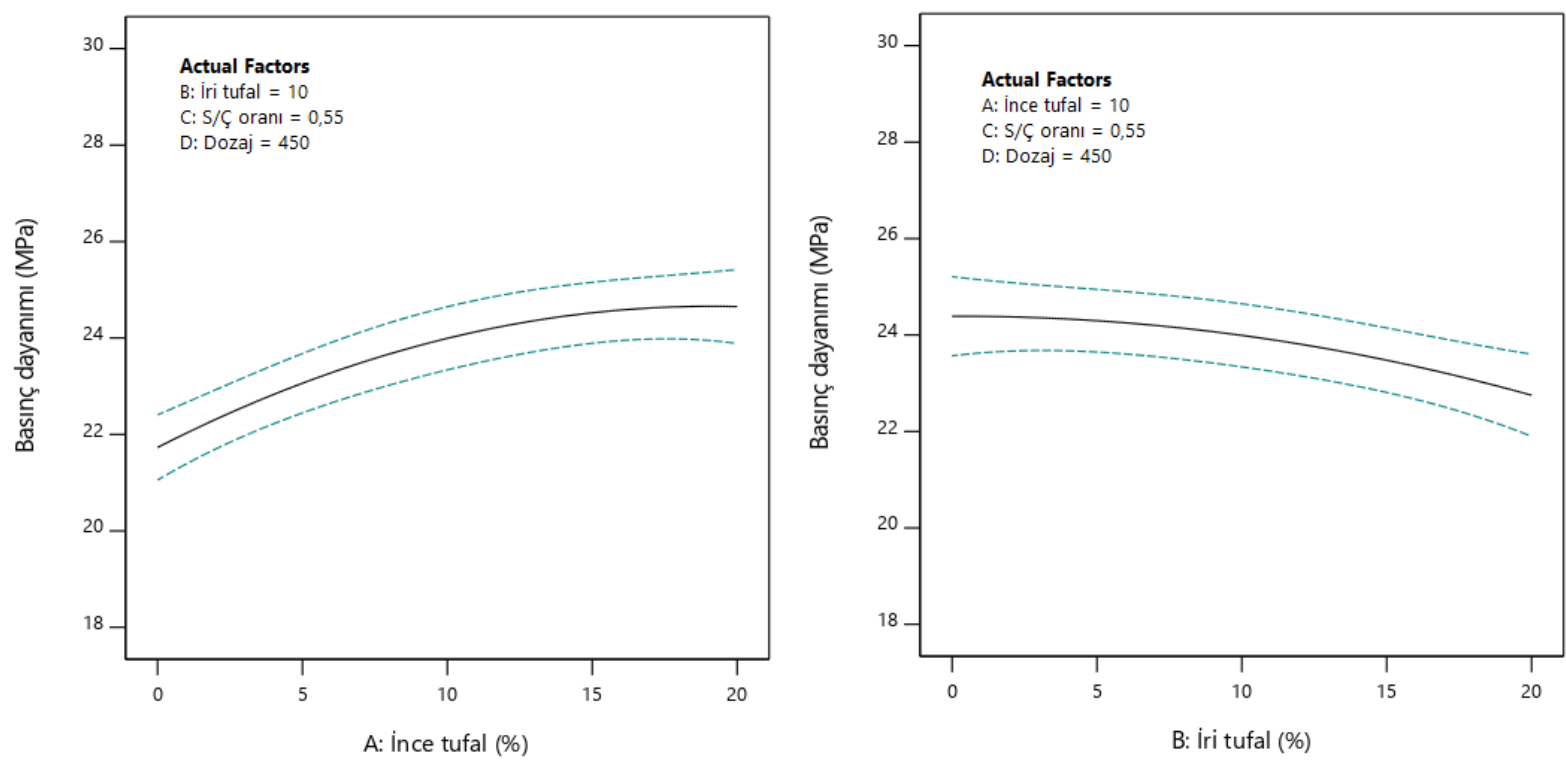

Şekil 7. İnce ve iri tufalin basınç dayanımına etkileri.

Tufalin basınç dayanımı üzerindeki etkisi Şekil 7'de verildi. Bu grafiklerden görüleceği üzere, karışım içindeki ince tufal oranı yaklaşık \% 15 e kadar dayanımda hızlı bir atış meydana getirirken $\% 20$ civarında bu artış hızı azalmıştır. İri tufal ilk başlarda az miktarda artışa sebep olurken özellikle $\% 5$ 'den sonra dayanımda düşüşe sebep olmuştur. 

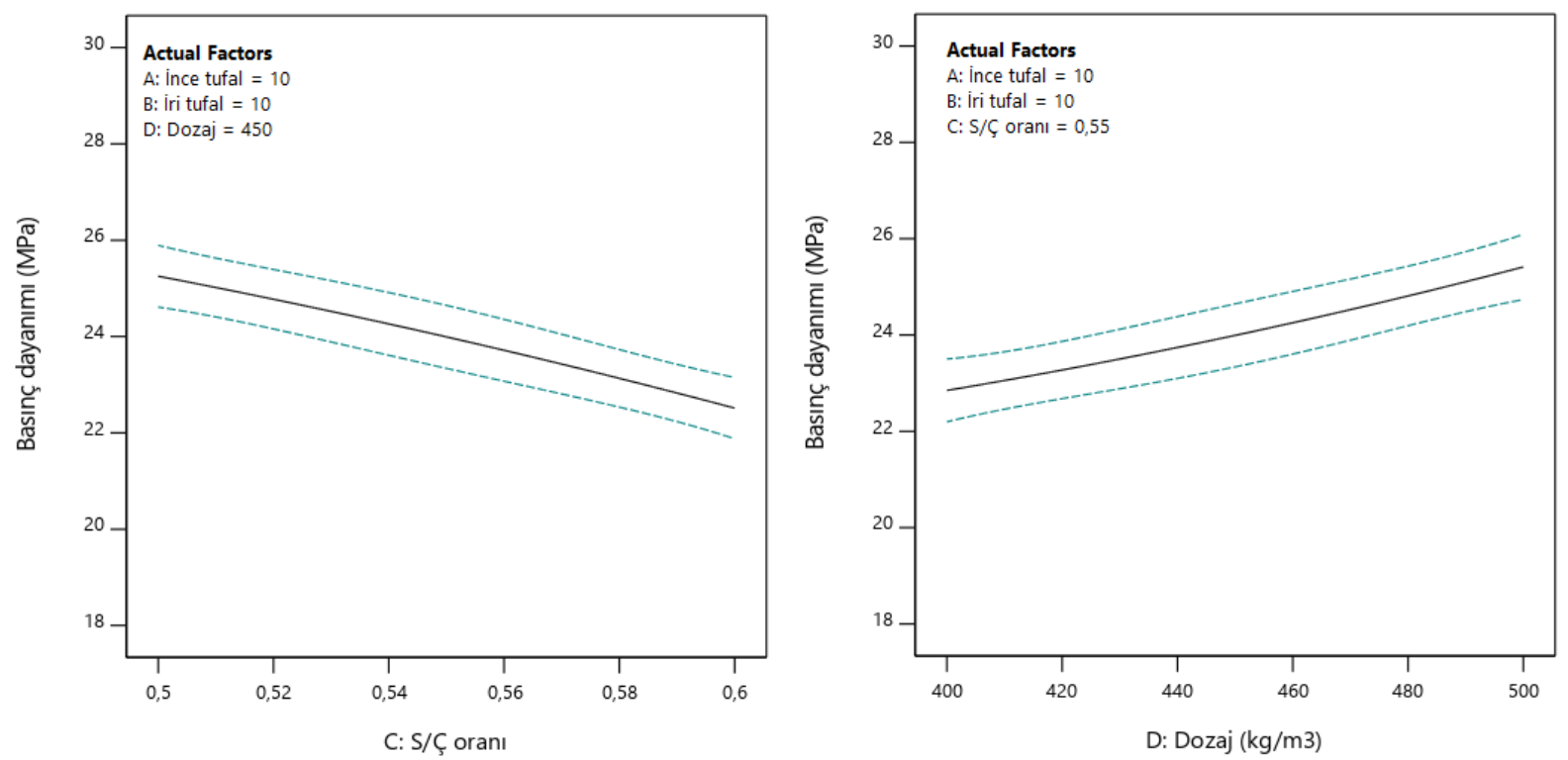

Şekil 8. S/Ç oranı ve dozajın basınç dayanımı üzerindeki etkileri.

S/Ç oranı ve dozajın etkisinin verildiği Şekil 8'den görüleceği üzere S/Ç oranındaki artış basınç dayanımını düşürmüş, fakat dozajdaki artış basınç dayanımını artırmıştır.

Denklem 4'de verilen model denklemin genetik algoritma ile optimizasyon işlemi gerçekleştirildi. Optimizasyon sürecinde çaprazlama oranı 0.2, popülasyon 60 ve iterasyon sayısı 2000 olarak alındı. Bu işlem sonucunda Tablo 5'de verilen optimum parametre seviyeleri ve bunlara karşılık gelen maksimum basınç dayanımı değeri elde edildi.

Tablo 5. Optimizasyon sonuçları

\begin{tabular}{|c|c|c|c|}
\hline Deney parametreleri & Parametre sembolü & Parametre değeri & $\begin{array}{c}\text { Tahmin edilen } \\
\text { maksimum basıç } \\
\text { dayanımı }(\mathrm{MPa})\end{array}$ \\
\hline İnce tufal (\%) & $\mathrm{A}$ & 19.68 & \multirow{2}{*}{29.41} \\
\hline İri tufal (\%) & $\mathrm{B}$ & 2.83 & \\
\hline $\mathrm{Su} /$ Çimento oranı & $\mathrm{C}$ & 0.50 & \\
\hline Çimento Dozaj1 $\left(\mathrm{kg} / \mathrm{m}^{3}\right)$ & $\mathrm{D}$ & 500 & \\
\hline
\end{tabular}

Genetik algoritma sonucunda elde edilen optimum parametre seviyeleri ve tahmini sonucun güvenirliliğinin belirlenebilmesi için Tablo 5'de verilen parametre seviyelerine göre doğrulama deneyi yapılarak kıyaslanmıştır. Tablo 6'da verilen doğrulama deneyi ve tahmini sonuç kıyaslandığında \%97 benzerlik çıkmıştır. Bu değer oluşturulan modelin ve optimizasyon işleminin güvenilirliğini göstermektedir.

Tablo 6. Optimum parametre seviyeleri ve deney sonuçları

\begin{tabular}{|c|c|c|c|c|c|}
\hline \multicolumn{4}{|c|}{ Optimum değer parametreleri } & \multicolumn{2}{c|}{ Basınç dayanımı (MPa) } \\
\hline $\begin{array}{c}0-0,25 \text { Tufal } \\
(\%)\end{array}$ & $\begin{array}{c}0,25-1 \text { Tufal } \\
(\%)\end{array}$ & $\begin{array}{c}\text { S/Ç } \\
(\%)\end{array}$ & $\begin{array}{c}\text { Dozaj } \\
(\mathrm{kg})\end{array}$ & $\begin{array}{c}\text { Tahmini } \\
\text { sonuç }\end{array}$ & $\begin{array}{c}\text { Doğrulama } \\
\text { deneyi sonucu }\end{array}$ \\
\hline 19.68 & 2.83 & 0.50 & 500 & 29.41 & 28.68 \\
\hline
\end{tabular}

\section{Sonuç ve Öneriler}

Bu çalışmada, tufal ilaveli harçların YYY ve genetik algoritma ile basınç dayanımının optimizasyonu yapıldı. Yanıt değeri olarak basınç dayanımını verecek kuadratik model denklem oluşturuldu ve genetik algoritma ile 
optimum parametre seviyeleri belirlendi. YYY analizleri ve genetik algoritma optimizasyonu neticesinde aşağıdaki sonuçlara ulaşılmıştır.

1. Deneysel verilerin analizleri sonucunda, ince tufal oranı ve dozajdaki artış basınç dayanımını olumlu yönde etkilerken, S/Ç oranı ve iri tufal oranındaki artış ise olumsuz yönde etkilediği görülmüştür.

2. Deneysel verilerden elde edilen kuadratik model incelendiğinde, $R^{2}=0.98$ ve $R^{2}{ }_{\text {adj }}=0.96$ olduğu görülür. $\mathrm{Bu}$ değerler modelden elde edilecek her yanıtın parametre yüzeyinde anlamlı bir karşılığının olduğunun ve güvenilir olduğunun göstergesidir.

3. Yapılan varyans analizi (ANOVA) sonucunda, oluşturulan kuadratik modelin F oranının 45.37 ve $\mathrm{P}<$ 0.0001 olması oluşturulan kuadratik denklemin anlamlı olmasını gösterir. Ayrıca $\mathrm{R}^{2}$ ve $\mathrm{R}^{2}$ adj değerlerinin de $\% 95$ üstünde olması modelin güvenirliliğini ve modelden elde edilecek her değerinin parametrelerle tutarlı olarak açıklanabileceğinin göstergesidir.

4. Varyans analizi incelendiğinde; $\mathrm{A}, \mathrm{B}, \mathrm{C}, \mathrm{D}, \mathrm{AC}$ ve $\mathrm{A}^{2}$ nin $\mathrm{P}$ değerlerinin 0.05 'den küçük olduğu görülür. $\mathrm{Bu}$ durum model denklem sonucunda bu değerlerin daha fazla etkili olacağının bir göstergesidir.

5. Yanıt (Basınç dayanımı) üzerine tufalin etkisi incelendiğinde, ince tufal oranının \% 15'e kadar dayanımı olumlu yönde etkilemesine karşın \%15-20 aralığın da bu olumlu etkinin zayıfladığı görüldü. İri tufalin ise ilk başlarda dayanımı olumlu yönde etkilemesine karşın \%5 lere yaklaştığı andan itibaren ters yönde etkilediği görüldü. Bu durum yaklaşık optimum değer açısından ince tufalin \% 20, iri tufalin ise \%1-3 oranlarında olduğunu gösterir.

6. S/Ç oranı ve dozajın yanıt üzerine etkileri incelendiğinde, $\mathrm{S} / \mathrm{Ç}$ oranındaki artışın basınç dayanımına olumlu bir etsinin olmadığı, dozajdaki artışın ise olumlu yönde etkilediği görüldü. Bu parametrelerin yaklaşık optimum değerleri $\mathrm{S} / C ̧$ oranının 0.50 , dozajın ise $500 \mathrm{~kg} / \mathrm{m}^{3}$ olabileceği tahmin edilebilir.

7. Genetik algoritma yardımıyla yapılan optimizasyon sonucunda, ince tufal \%19.68, iri tufal \%2.83, S/Ç oranı 0.50 ve dozaj $500 \mathrm{~kg} / \mathrm{m}^{3}$ optimum parametre değerleri belirlendi. Bu optimum değerlere göre tahmini maksimum basınç dayanımını ise $29.41 \mathrm{MPa}$ olarak bulundu. Optimum parametre değerleri ile tahmin edilen değerlerin uyumlu olması yapılan genetik algoritmanın da güvenilir olduğunun göstergesidir.

8. Optimizasyon sonucu elde edilen parametre değerlerine uygun olarak harç numunesi hazırlanarak doğrulama deneyi yapıldı ve basınç dayanımı $28.68 \mathrm{MPa}$ olarak belirlendi. Doğrulama deneyi sonucu ile optimizasyon sonucu olan 29.41 MPa tahmini basınç dayanımı değeri kıyaslandığında yaklaşık \%98'lik benzerlik bulundu. Bu sonuç oluşturulan modelin doğruluğunu ve yapılan genetik algoritmanın güvenilir olduğunu gösterir.

Deneysel çalışma ve teoriksel analizler neticesinde; atık çelik tufalin harçlarda kullanımının hem ekonomik hem de çevresel faydalarının yanı sıra basınç dayanımı açısından da olumlu etkilerinin olduğu görüldü. Yanıt yüzey yöntemi ve genetik algoritmanın birlikte kullanımı neticesinde daha az deneysel veri ile sonuca ulaşılmasının mümkün olduğu yapılan bu çalışmada görüldü. Ayrıca, deney sonuçlarının ve parametrelerin sonuç üzerindeki etkilerinin yorumlanabilmesi açısından çok faydalı olduğu kanaatine varıldı.

\section{Kaynaklar}

[1] Arıcı E, Keleştemur O. Tufal katkılı harçların basınç dayanımının taguchi metodu ile analizi. Fırat Üniv. Müh. Bil. dergisi 2018; 30(3): 145-151.

[2] Gupta LK, Vyas AK. Impact on mechanical properties of cement sand mortar containing waste granite powder. Constr Build Mater 2018; 191: 155-164.

[3] Sevim UK, Öztürk M, Önturk S, Bankır MB. Utilization of boron waste borogypsum in mortar. Journal of Building Engineering 2019; 22: 496-503.

[4] Sen R, Maan A, Goyal U, Birdhaniya A, Pandel U. In crucible reduction of mill scale by lean grade coal: Study of time, temperature and arrangement for optimum reduction conditions. Mater Today 2018; 5: 7256-7263.

[5] Kayılı MT, Çelebi G, Güldaş A. Yapı sektöründe atık kullanımına ilişkin bir inceleme: demir- çelik üretim atıkları. Uluslararası Malzeme Bilimi ve Teknolojisi Konferansi; 6-8 Nisan 2016; Nevşehir, Türkiye: IMSTEC'16.

[6] Delil AD, Yıldırım D, Köleli N. Çelikhane cürufundan ve tufalinden bitki besin elementlerinin geri kazanımı ve bu elementlerin bitki büyümesine etkisi. Journal of Engineering and Science 2017; 5(1): 01-07.

[7] El-Hussiny NA, Mohamed FM and Shalabi MEH. Recycling of Mill Scale in Sintering Process. SCI Sinter 2011; 43: 2131.

[8] Sekunowo OI, Durowaye SI, Lawal GI. Synthesis and characterisation of iron millscale particles reinforced ceramic matrix composite. Journal of King Saud University - Engineering Sciences 2019; 31(1): 78-85.

[9] Rooholamini H, Hassani A, Aliha MRM. Evaluating the effect of macro-synthetic fibre on the mechanical properties of roller-compacted concrete pavement using response surface methodology. Constr Build Mater 2018; 159: 517-529. 
[10] Moodi Y, Mousavi SR, Ghavidel A, Sohrabi MR, Rashki M. Using Response Surface Methodology and providing a modified model using whale algorithm for estimating the compressive strength of columns confined with FRP sheets. Constr Build Mater 2018; 183: 163-170.

[11] Ferdosian I, Camoes A. Eco-efficient ultra-high performance concrete development by means of response surface methodology. Cement Concrete Comp 2017; 84: 146-156.

[12] Mohammed B.S, Khed VC, Muhd Fadhil Nuruddin MF. Rubbercrete mixture optimization using response surface methodology. J Clean Prod 2018; 171: 1605-1621.

[13] Öztürk ZB, Ay N. Yanıt yüzey metodu ile porselen karo küçülmesinde ergiticilerin optimizasyonu. Eskişehir Osmangazi Üniversitesi Mühendislik Mimarlık Fakültesi Dergisi 2012; 25(2): 57-66.

[14] Koç B, Kaymak F. Yanıt yüzey yöntemi ve gıda işleme uygulamaları. Gıda 2010; 35(1): 1-8.

[15] Mohammed BS, Fang OF, Hossain KMA, Lachemi M. Mix proportioning of concrete containing paper mill residuals using response surface methodology. Constr Build Mater 2012; 35: 63-68.

[16] Sönmez F, Başak H, Baday Ş. Haddeleme işleminin yüzey yanıt yöntemi ile analizi. GU J Sci, Part C 2016; 4(4): $275-283$.

[17] Elrehim MZA, Eid MA, Sayed MG. Structural optimization of concrete arch bridges using genetic algorithms. Ain Shams Engineering Journal 2016; 10: 1-10.

[18] Karahan AM, Özdağlar D. Su dağıtım sistemlerinin genetik algoritma ile optimizasyonu. DEÜ Mühendislik Fakültesi Fen ve Mühendislik Dergisi 2004; 6(3): 1-18.

[19] Zorlu H., Sunca Ş., “Genetik algoritma kullanılarak ağırlıklandırılmış myriad filtrelerinin optimizasyonu”, International Journal of Multidisciplinary Studies and Innovative Technologies 2017; 1(1): 9-14.

[20] TS EN 197-1, Çimento- Bölüm 1: Genel çimentolar bileşim, özellikler ve uygunluk kriterleri. Türk Standartları Enstitüsü, Türkiye, 2012 .

[21] TS EN 196-1: Çimento Deney Metotları. Türk Standartları Enstitüsü, Türkiye, 2002.

[22] Turan MD, Altundoğan HS. Hidrometalurjik araştırmalarda yanıt yüzey yöntemlerinin (YYY) kullanımı. Madencilik 2011; 50(3): 11-23. 